\title{
Concepciones del mundo en el Capitalismo Contemporáneo: el tecno-emprendedorismo en las empresas unicornio argentinas ${ }^{1}$
}

\section{Denise Krepki ${ }^{2}$}

Recibido: 25/05/2021; Aceptado: 17/08/2021.

Cómo citar: Krepki, D. (2021) Concepciones del mundo en el Capitalismo Contemporáneo: el tecnoemprendedorismo en las empresas unicornio argentinas. Revista Hipertextos, 9(16), 115-130. https://doi.org/10.24215/23143924e043

Resumen. La racionalidad neoliberal ha consolidado la figura del sujeto emprendedor como parte de un sentido común. Sobre todo, toma una gran relevancia dentro del sector ligado a empresas de uso intensivo de tecnología. En este sentido, tomamos los aportes de Antonio Gramsci, para problematizar esta construcción o concepción de mundo alrededor de la figura del sujeto emprendedor, el cual se fortalece en el capitalismo contemporáneo. Las empresas denominadas como "unicornios" juegan un papel central en la construcción y consolidación de lo que denominaremos como tecnoemprendedorismo. Este trabajo es parte de una investigación en curso y se centra en el análisis de las prácticas, narrativas y significantes que amalgaman a la acción emprendedora con la innovación tecnológica. Para esto, tomaremos el caso de la empresa multinacional argentina, Globant, la cual produce y vende servicios informáticos a clientes. Nuestra estrategia metodológica se fortalece desde un enfoque cualitativo, a partir de un proceso sistemático de compilación de distintas intervenciones de los CEOs de la empresa, tanto en medios audiovisuales, medios gráficos, conferencias en eventos públicos, como articulaciones de dichos tecno-emprendedores entre sí y con funcionarios gubernamentales.

Palabras clave: tecno-emprendedorismo, Globant, tecnología, meritocracia, neoliberalismo.

Sumario. 1. Introducción. 2. El mito del garaje: "el sueño americano" emprendedor. 3. Endeavor, la fundación del emprendedor. 4. BA al mundo, el foro de Silicon Valley. 5. Reflexiones finales.

\footnotetext{
${ }^{1}$ Una versión preliminar de este trabajo ha sido presentada como ponencia en el VI Congreso de la Asociación Latinoamericana de Antropología, Desafíos emergentes: Antropologías desde América Latina y el Caribe, 23 al 28 de noviembre de 2020, modalidad virtual.

2 Licenciada en Relaciones del Trabajo por la Universidad de Buenos Aires. Actualmente doctoranda en Antropología y becaria del Centro de Estudios e Investigaciones Laborales (CEIL) dependiente del Consejo Nacional de Investigaciones Científicas y Técnicas (CONICET). Docente del curso "Nuevas tecnologías y trabajo" en la Capacitación Universitaria Extracurricular en "Problemas Contemporáneos del Trabajo", Facultad de Filosofía y Letras, UBA. Miembro del Observatorio de Economía Digital desde 2019 e integra proyectos de investigación científica sobre temas de trabajo, tecnologías digitales y empresas. Contacto: dkrepki@gmail.com
} 


\section{Worldviews in Contemporary Capitalism: techno-entrepreneurship in Argentinean unicorn firms}

Abstract. Neoliberal rationality has consolidated the figure of the entrepreneurial subject as part of common sense. Above all, it is highly relevant within the sector linked to technology-intensive companies. In this sense, we take the contributions of Antonio Gramsci, to problematize this construction or conception of the world around the figure of the entrepreneurial subject, which is empowered in contemporary capitalism. The companies known as "unicorns" play a central role in the construction and consolidation of what we will call techno-entrepreneurship. This work is part of an ongoing investigation and focuses on the analysis of practices, narratives and signifiers that amalgamate entrepreneurial action with technological innovation. For this, we will study the case of the Argentine multinational company, Globant, which produces and sells computer services to clients.

Our methodological strategy is based on qualitative approximation, from a systematic process of compiling different interventions of the company's CEOs, both in audiovisual media, graphic media, conferences at public events, as well as articulations of said techno-entrepreneurs with each other and with government officials.

Keywords: techno-entrepreneurship, Globant, technology, meritocracy, neoliberalism

\section{Perspectivas do mundo no capitalismo contemporâneo: o tecno-empreendedorismo nas empresas unicornas argentinas.}

Resumo. A racionalidade neoliberal consolidou a figura do sujeito empreendedor como parte do senso comum. Acima de tudo, é altamente relevante dentro do setor ligado às empresas intensivas em tecnologia. Nesse sentido, tomamos as contribuições de Antonio Gramsci, para problematizar essa construção ou concepção de mundo em torno da figura do sujeito empreendedor, que se fortalece no capitalismo contemporâneo. As empresas conhecidas como "unicórnios" desempenham um papel central na construção e consolidação do que chamaremos de tecnoempreendedorismo. Este trabalho faz parte de uma investigação em andamento e tem como foco a análise de práticas, narrativas e significantes que amalgamam a ação empreendedora com a inovação tecnológica. Para isso, tomaremos o caso da multinacional argentina Globant, que produz e vende serviços de informática para clientes.

A nossa estratégia metodológica é reforçada a partir de uma abordagem qualitativa, a partir de um processo sistemático de compilação de diferentes intervenções dos CEOs da empresa, quer nos meios audiovisuais, nos meios gráficos, nas conferências em eventos públicos, bem como nas articulações dos referidos tecnoempresários entre si e com funcionários do governo.

Palavras-chave: tecno-empreendedorismo, Globant, tecnologia, meritocracia, neoliberalismo

\section{Introducción}

"Ser un emprendedor no es solo una profesión o un llamado, no es solo un modo de actividad económica o un algo consagrado por el derecho privado.

Deber y querer ser emprendedor es también un modo de concebirse y de orientarse a sí mismo y a los otros: es decir, se trata de una forma de subjetivación." (Ulrich Bröckling, 2015, p. 13)

El 31 de agosto del año 2020 se publica en el boletín oficial argentino la legislación que abre camino a la construcción de un Parque Tecnológico en la provincia de Misiones (al noreste de 
Argentina) que recibe el nombre de: "Silicon Misiones"3. Este complejo caracterizado como un centro regional para la innovación y desarrollo de alta tecnología comprende la confluencia de acción de distintos sectores nacionales tales como: el científico, el tecnológico, el gubernamental, el educativo y el empresarial ${ }^{4}$ y acuña como uno de sus objetivos "otorgar infraestructura edilicia y de servicios, puesta al alcance de emprendedores y empresarios". Este proyecto, a su vez, incorpora el desarrollo de la "Universidad del conocimiento" dentro del complejo, con el objetivo de "generar perfiles altamente capacitados en el desarrollo web full stack, con una mirada a la economía del conocimiento, el delivery de software, y el emprendedorismo" (Misiones Online, 2020). En esta línea, tanto en el cuerpo de la legislación, como en el proyecto educativo que se encuentra en desarrollo en este último tiempo, la figura del sujeto emprendedor y la búsqueda por "potenciar la capacidad innovadora y emprendedora" son categorías recurrentes. De hecho, una de las últimas actividades realizadas por streaming a través de la plataforma de You Tube fue denominada: "el camino del emprendedor" y suponía una serie de pautas y reglas para poder desempeñar esa travesía emprendedora de la mejor forma posible (Silicon Misiones, 2020). La pregunta que se nos suscita a partir de tales postulados es: ¿Qué sentidos y significados se construyen alrededor de la figura del emprendedor en ámbitos ligados al desarrollo tecnológico? ¿Cuáles son las características que definen a un emprendedor en este sector? ¿Por qué razones se busca potenciar perfiles emprendedores diferenciándolos de perfiles empresarios?

En las últimas décadas, los estudios sobre el emprendedorismo se han robustecido diversificando las líneas de análisis. Así, desde la psicología (Lopez Puga y García, 2011), la sociología (Brökling, 2015), la economía (Schumpeter, 1997) y la antropología (Bueno Castellanos, 2020) se ha intentado delinear características de los sujetos emprendedores desde distintas perspectivas y momentos históricos. La heterogeneidad de acepciones del emprendedorismo están relacionadas con una multiplicidad de fines en la acción de emprender que no solo se vincula con el ambiente de los negocios, sino que admite perfiles emprendedores que tienen el incentivo de buscar el bien común, soluciones que intenten resolver el deterioro ecológico (Carmen Bueno Castellanos, 2020) o que reconocen en la autogestión una salida frente al desempleo (Santos Ortega, 2014), entre otras. En definitiva, cada perfil emprendedor se encuentra atravesado por determinados contextos socio-culturales, históricos, políticos y económicos.

Ahora bien, en el capitalismo contemporáneo ${ }^{5}$, el inminente avance de Internet y del desarrollo de tecnologías digitales dota a las empresas vinculadas al uso intensivo de tecnología

\footnotetext{
${ }^{3}$ Ley VIII-78. Sistema Argentino de Información Jurídica, Ministerio de Justicia y Derecho Humanos, Argentina, 13 de agosto de 2020.

${ }^{4}$ Podríamos afirmar que este ejemplo resulta una confirmación empírica de lo que Eric Sadin (2017) pronosticaba como una silicolonización del territorio con la construcción de valles del conocimiento en los distintos continentes "destinados a favorecer la creación de empresas start-up, a unir a los distintos actores y a anexarse sin demora al tren de la economía de datos" (2017, p. 33).

${ }^{5}$ La definición de una nueva etapa digital en el capitalismo contemporáneo suscitó un debate teórico a partir del cual surge una extensa serie de neologismos que intentan marcar una cartografía compleja de desplazamientos en torno a las prácticas y conceptos tradicionales de la anterior etapa industrial y permiten imaginar la cristalización de un nuevo paradigma económico: capitalismo de plataformas (Srnicek, 2018), capitalismo de vigilancia (Zuboff, 2013), capitalismo informacional (Castells, 2017), capitalismo cognitivo (Vercellone, 2011), capitalismo electrónicoinformático (Ribeiro, 2017), entre otras.
} 
de una indudable relevancia. En Argentina, las empresas denominadas como unicornios ${ }^{6}$ juegan un papel central en la construcción y consolidación de un sujeto emprendedor ligado a la innovación tecnológica. Teniendo en cuenta que quienes conducen estas empresas definen su trayectoria empresarial a partir del emprendedorismo, en el presente trabajo nos interesa recuperar esa concepción de sujeto emprendedor agenciada por estos actores. Esta nueva fracción de emprendedores vinculados con el uso intensivo de las nuevas tecnologías digitales y con una relación estrecha y compleja con los capitales financieros globales, toma como modelo a las empresas emblemas de Silicon Valley diferenciándose fuertemente de los sectores concentrados más tradicionales (Ventrici, Palermo, 2020). El ejemplo de Silicon Misiones, anteriormente mencionado, podría pensarse como un espejo de prácticas y discursos que vienen construyéndose dentro de la industria hace décadas y que despliega una robusta filosofía empresarial que potencia la innovación como característica diferencial. Si bien encontramos aproximaciones a la temática con definiciones tales como emprendedor tecnológico (Veciana, 1989), emprendedor informacional (Feldman, 2018), utilizaremos la categoría de tecnoemprendedor para definir a una elite empresarial que desde sus prácticas, narrativas y discursos consolida un modo de subjetivación emprendedora ligado a la innovación, la audacia y a la austeridad que traspasa los límites físicos de sus propias empresas. Por consiguiente, caracterizamos al tecno-emprendedorismo desde la categoría gramsciana de concepción del mundo resaltando la trascendencia del discurso y las tramas de relaciones que tales tecnoemprendedores construyen en múltiples espacios de intervención. En este sentido, sostenemos que el tecno-emprendedorismo como concepción del mundo de las clases empresarias del sector tecnológico-informático entrama un modo de pensar y de actuar en un determinado momento histórico (Gramsci, 2000a) en el cual la tecnología es puesta como la solución más eficaz frente a problemáticas de la vida cotidiana ${ }^{7}$.

Por lo expuesto hasta aquí, proponemos una continuidad analítica con un trabajo anterior en el que posamos la mirada sobre los sentidos que el tecno-emprendedorismo dinamiza en los ámbitos de trabajo desde la perspectiva de les trabajadores. No obstante, el siguiente trabajo propone una descripción y análisis del tecno-emprendedorismo desde la perspectiva empresariaemprendedora. Con el objetivo de reconstruir cómo se forja esta concepción del mundo tecnoemprendedora a nivel local en sectores ligados al desarrollo de tecnología y servicios informáticos, recuperamos el caso de la segunda empresa unicornio con mayor valuación bursátil $^{8}$ de Argentina: Globant ${ }^{9}$.

\footnotetext{
${ }^{6}$ Las empresas "unicornio" son empresas basadas en el uso intensivo de la tecnología, que comienzan como start ups y en períodos relativamente cortos alcanzan una cotización superior a 1000 millones de dólares en los mercados de inversión privada. Argentina cuenta actualmente con cinco empresas en esa categoría: Mercado Libre, Globant, OLX, Despegar.com y Auth0.

${ }^{7}$ La pandemia resulta un caso paradigmático si pensamos en el hecho de que la forzada digitalización de muchos aspectos de la vida cotidiana potenció esa visión tecnófila. Así, desde la utilización de aplicaciones para monitorear casos de COVID-19, consultas médicas y seguimiento de casos on-line, permisos digitales de circulación, la preponderancia de las tecnologías digitales fue situada como una solución frente a la crisis que desató el proceso de la pandemia.

${ }^{8}$ De las empresas unicornio argentinas, Mercado Libre es la compañía de mayor valor en la bolsa de Estados Unidos (NASDAQ) con una valuación bursátil de US\$100.000 millones (marzo 2021), triplicando su piso del año anterior. En segundo lugar, la empresa Globant registra actualmente una valuación de US\$ 8.700 millones siendo su máximo valor alcanzado desde su creación en 2003. Las valuaciones de ambas empresas reflejaron un crecimiento acelerado en el contexto de pandemia del COVID-19.

${ }^{9}$ Globant, empresa multinacional argentina de IT y desarrollo de software (software factory). Opera actualmente en 17 países con más de 40 oficinas. Fue creada en el año 2003 y actualmente cuenta con una dotación de 20.000
} 
El artículo se estructura en cuatro apartados. En primer lugar, comenzaremos describiendo una de las características más recurrentes dentro de los discursos tecno-emprendedores que refiere enaltecimiento de los garajes como génesis emprendedora de sus unidades productivas. Nos adentraremos en el mencionado "mito del garaje" para dar cuenta de cómo ese mito fundante emprendedor con faro en Silicon Valley se traslada a los discursos y prácticas que explicitan los comienzos de la empresa Globant. Desde este caso de estudio, abordaremos las articulaciones que los denominados tecno-emprendedores forjan con otras instituciones y actores. Retomamos, por tanto, a la Fundación Endeavor Argentina como uno de los espacios institucionales que nuclea y estrecha la relación entre emprendedores de distintos sectores y los ubica como casos de éxito en sus actividades de divulgación abiertas al público. En tercer lugar, haremos mención al "Foro de Silicon Valley" realizado en la Ciudad de Buenos Aires en el mes de diciembre del año 2017 bajo el patrocinio del Gobierno de la Ciudad de Buenos Aires, como una fotografía que retrata la imbricación del tecno-emprendedorismo con discursos gubernamentales neoliberales latinoamericanos. Finalmente, retomaremos los ejes centrales y categorías del análisis en las reflexiones finales.

La metodología empleada se centra en una aproximación cualitativa que se sustenta en un proceso sistemático de compilación de distintas intervenciones de los CEOs de la empresa, tanto en medios audiovisuales, medios gráficos, redes sociales, conferencias en eventos públicos, como interacciones entre distintos tecno-emprendedores y con funcionarios gubernamentales.

\section{El mito del garaje: "el sueño americano" emprendedor}

Si pensamos al emprendedorismo anclado a la práctica de los grandes imperios tecnológicos, principalmente situados en Silicon Valley, debemos remitirnos al inicio de estas historias. En los orígenes de la gran mayoría de las empresas que conforman al valle de silicio californiano, existe una espacialidad común que ha sido dotada de una sacralidad inimaginable ${ }^{10}$.Un lugar, en general, ubicado en subsuelos, con baja iluminación, muchas veces utilizado como depósito, poco visitado pero que adquiere luminosidad concreta y simbólica cuando una idea visionaria se gesta en él: el garaje.

empleados y empleadas. Es considerada una de las once "empresas unicornios argentinas" junto con Mercado Libre, OLX, Despegar.com, Auth0, Vercel, Aleph, Mural, Bittfarms y Ualá.

${ }^{10}$ En el año 2006, Google compra el garaje donde sus dos fundadores comenzaron a poner en práctica el buscador. En 2018, con motivo de los 20 años de la compañía, se dispuso habilitar un tour virtual por el garaje a través de Google Street View. La ambientación del mismo se correspondía con el momento en que Larry Page y Sergey Brin crearon la compañía. Es, a su vez, un punto turístico para quienes visiten el valle, así como el garaje de Hewlett Packard (HP), el cual, si bien no cuenta con acceso abierto al público, es considerado como el lugar de nacimiento de Silicon Valley y un símbolo de emprendimiento. En Argentina, Marcos Galperín (ex CEO de Mercado Libre) denomina al garaje donde inicia la empresa como "el museíto". Un sitio emblema de la cultura empresarial de Mercado Libre, que mantiene la estética de sus inicios y mucho del mobiliario de esa época (pc de escritorio, antiguos logos de la empresa y hasta documentos). Este mismo puede ser visitado por las y los trabajadores de la compañía. 
Imagen $\mathbf{n}^{\mathbf{0}} \mathbf{1}$ : Imagen publicada por una agencia de marketing (2020)

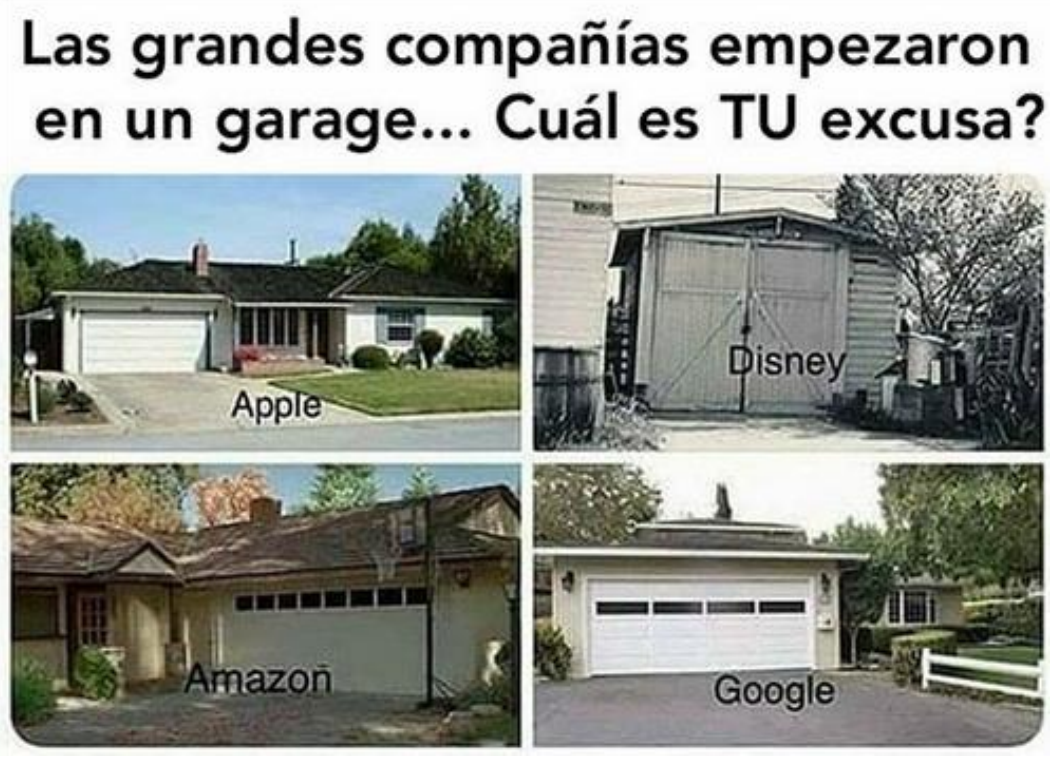

Fuente: Facebook Webs al instante

El mito del garaje es reivindicado por muchas de las empresas del valle como el lugar donde se forjó su nacimiento como gurúes tecnológicos ${ }^{11}$. Si bien, no todas ellas comparten en la materialidad concreta este mito, así como tampoco iniciaron su carrera sin financiamiento alguno ("de la nada misma"), igualmente deciden compartir este discurso que romantiza a un grupo de aficionados a la tecnología escribiendo su historia de ceros y unos en este espacio ${ }^{12}$. El garaje se ubica como escenario que narra la historia de una performatividad emprendedora masculina ${ }^{13}$ ejercida por un grupo de expertos, conocidos, colegas, amigos encantados por la tecnología y dispuestos a tomar riesgos y desafíos para materializar su idea innovadora a partir de procesos de prueba y error. Una aplicación de transporte, un buscador global, ventas por internet, transacciones bancarias digitales, venta de servicios de software, entregas de comida por medio de plataformas.

El garaje -como espacio conceptual creado a la imagen de los valores que se intenta transmitir- expresa la libertad que todo individuo tiene para emprender, solo limitada por su creatividad, reponiendo una de las conquistas culturales más importantes del neoliberalismo: el valor de emprender (Palermo et. al., 2020, p. 10).

A nivel local, es posible rastrear experiencias similares dentro del rubro, pero con matices propios de la coyuntura nacional. Actualmente, existen en Argentina cinco empresas de

11 Algunos ejemplos son: Apple, Amazon, Disney, Hewlett Packard y Harley-David, y Google.

12 Estas resultan historias sumamente conocidas a nivel global encontrando múltiples referencias en ficciones audiovisuales, notas y artículos periodísticos especializados, avisos publicitarios, por citar algunos ejemplos. La popular serie de televisión estadounidense de HBO, "Silicon Valley", retrata la historia de cinco expertos que trabajan en la industria tecnológica que utilizan su hogar para montar un nuevo negocio a partir del descubrimiento de un algoritmo de compresión de datos. Desde la sátira y la comedia, narran el comienzo y su posterior trayectoria como emprendedores tecnológicos mostrando al garaje y la casa como su primer espacio de trabajo, así como la complejidad de competir con grandes empresas consolidadas en la industria tecnológica.

${ }^{13}$ Para un análisis sobre el mito del garaje y el ejercicio de la masculinidad ver: Palermo, H.; Radetich, N. y Reygadas, L. (2020). 
tecnología denominadas "unicornios"14 las cuales tienen una ligazón muy estrecha con esta filosofía emprendedora siliconiana: Mercado Libre, Globant, OLX, Despegar y AuthO ${ }^{15}$. Tomando el caso de la empresa Globant, el mito del garaje se ve modificado a partir de un cambio en la espacialidad en la que se origina la empresa, pero la filosofía emprendedora y la ficticia austeridad, sigue rigiendo este proceso. Al decir de sus socios fundadores, Globant nace en un bar porteño en 2003 con un presupuesto inicial de 5000 dólares y una charla entre amigos. Una escena de la vida cotidiana que es presentada como la semilla de la planificación de la segunda empresa más valiosa del país. En una entrevista realizada por el medio emprendores.tv, Guibert Englebienne, CEO fundador de la compañía y CTO, describía ese proceso de esta manera:

La historia comienza en un bar ubicado a dos cuadras. Un bar que yo digo que es como tierra santa para los emprendedores. Y decidimos en ese momento focalizarnos en crear una compañía que pudiera ser líder inicialmente de Latinoamérica, que pudiera poner bandera en el mundo de la tecnología. Demostrar aquello de lo que somos capaces y que además buscara llevar oportunidades a donde la gente quisiera vivir. $\mathrm{Y}$ ahora tenemos 40 oficinas en 14 países y en Argentina estamos en 11 ciudades (Emprendiendo TV, 2019).

La idea de crear una compañía líder, como menciona Guibert, no surge de la noche a la mañana, sino que se ve atravesada por las propias trayectorias personales de estos cuatro ingenieros. Tres de ellos reconocen experiencias de emprendimientos familiares que surgen al calor de los vaivenes de la coyuntura histórica y económica argentina. El desempleo, la hiperinflación son algunas de las causas que mencionan como puntapiés de los emprendimientos llevados adelante por sus progenitores, quienes tenían la posibilidad y los recursos para poder llevarlos a cabo. De esta manera, la acción de emprender no les era ajena cuando tuvieron ese encuentro en el bar en el que bosquejan la empresa. Ahora bien, es interesante la metáfora que utiliza Guibert cuando recuerda a ese bar como "esa tierra santa de emprendedores". Esa espacialidad, que podía ser un garaje, un bar, un sótano o un local de comidas, representa uno de los principios emprendedores más divulgados: la idea de emprender desde cero. Es decir, la creencia de que cualquier persona tiene la posibilidad de construir una propuesta innovadora que introduzca un cambio cualitativo si lo desea y esté dispuesto a sortear los obstáculos propios del proceso. En este punto, la idea de la meritocracia articula perfectamente con este discurso. Las personas que asumen riesgos, desafíos, quienes se esfuerzan al máximo, son quienes progresan. Una cuestión de actitud más que de desigualdad de oportunidades o de asimetría sistémica. Una suerte de viralización de una cultura emprendedora bajo la cual se piensan las trayectorias tecnoemprendedoras como recorridos posibles, alcanzables $y$, ante todo, replicables. Como perfectamente sugiere Francois Dubet (2014) estas narrativas se fundamentan en un mito de la igualdad de oportunidades que se apoya sobre el imaginario de una competencia equitativa en la

\footnotetext{
${ }^{14}$ Se las identifica como empresas unicornios ya que comenzaron siendo empresas starts-up y en un corto periodo de tiempo alcanzaron un crecimiento económico mítico: una cotización mayor a los mil millones de dólares.

${ }^{15}$ La empresa Despegar.com debido a un agudo proceso de crisis generado a partir de la pandemia por Covid-19 deja de pertenecer a la categoría de empresas unicornios en el año 2020. Principalmente, su estrategia de negocios vinculada a la actividad turística se vio fuertemente afectada a partir del decreto de la situación de cuarentena mundial provocando un profundo desmejoramiento y pauperización de la situación laboral de les trabajadores (Palermo, Ventrici, Krepki, 2020). Sin embargo, con la apertura de vuelos nacionales e internacionales producida a lo largo del año 2020 y 2021, recupera parte de sus activos, así como la categoría de empresa unicornio.
} 
cual, dado que las oportunidades conciernen a los individuos, estos deben ser activos y movilizarse para merecerlas.

Soy co-fundador de Globant, una de las empresas de mayor crecimiento durante estos últimos 15 años. Somos una compañía nativa digital que transforma a las organizaciones líderes para que sobresalgan en esta era. Es un proceso desafiante, tal como lo fue para nosotros crecer de 4 fundadores juntos en un bar a una empresa con casi 10.000 colaboradores. Creo firmemente que el principal objetivo para un emprendedor debería ser replicarse a sí mismo. Si logramos que la gente actúe como un fundador, entonces, habremos creado una organización exponencial que no necesita de alguien presente en todas las áreas para asegurar su crecimiento (Guibert Englebienne, 2019).

Yo creo que el emprendedor es una forma de ser empresario. Sos un empresario que piensa como emprendedor. Tomando riesgos todos los días, empleando gente, haciendo las cosas como la ley manda, haciendo un montón de cosas que están puestas en discusión por la sociedad hoy sobre los empresarios (Martin Migoya, 2018).

Según expresan Migoya y Englebienne, ser emprendedor refiere a un nuevo modo de pensar y actuar en el ámbito empresarial que requiere ser replicado. Emprender, desde esta lógica, supone una revitalización de las prácticas empresarias y la encarnación de una subjetividad emprendedora en el mundo de los negocios: construir una concepción del mundo emprendedora. El lenguaje corporal y la estética de estos tecno-emprendedores intenta romper con el paradigma de la tradicional figura del empresario o del patrón, exponiendo actitudes descontracturadas, formas coloquiales y elocuentes de expresarse, vestimenta casual, jovial, con una actitud positiva, asumiendo riesgos y repitiendo la conocida frase de que "en las crisis están las oportunidades”. Un empresariado limpio, aséptico, tecnológico (Vanoli; Galliano, 2017) que se encarga de construir muy minuciosamente la percepción que se tiene de ellos. Así, la figura del tecno-emprendedor se presenta en estos últimos años como renovación institucional del mundo empresarial y del capitalismo (Santos Ortega, 2014).

Esta nueva generación empresaria ya no usa los valores del viejo empresariado, esta nueva generación empresaria tiene tres valores centrales: ultra competitividad, pensar en el largo plazo y el tercer valor innegociable, es mirar a la Argentina como una plataforma de despegue global, ir a comerse el mundo. Y les quiero contar que el mundo es mucho más meritocrático de lo que ustedes piensan (Martín Migoya, 2019).

Retomando la idea de que las concepciones del mundo no remiten a una singularidad, sino que se encuentran en disputa o contradicción con otras que determinan la pertenencia a un agrupamiento que comparte un mismo modo de pensar y actuar (Gramsci, 2000), en la cita anterior podemos encontrar dos concepciones del mundo en tensión. La nueva generación empresaria, en palabras de Migoya, busca legitimar a ese sujeto emprendedor intentando despegarse de las viejas recetas del empresariado local tradicional y transgrediendo los vicios (asociados principalmente a la corrupción y a la burocratización) que esa generación asociada al pasado presuponía. Esto no les quita el mote de empresarios, sino que advierte un nuevo grupo de empresarios con actitud emprendedora que los dota de espíritu fresco, relajado, flexible, carismático y a la vanguardia de las denominadas empresas y empleos del futuro. Al decir de 
Jorge Moruno (2015), encontramos una parafernalia ideológica que sitúa todo lo vinculado al espíritu emprendedor como un elemento de ruptura social con lo establecido. Esta nueva lente para los negocios, modela comportamientos, modos de pensar y genera su propio manifiesto de éxito en las nuevas generaciones empresarias. Sin embargo, admite legitimidad en lo que podríamos caracterizar como sectores subalternos. La capacidad de emprender tiene buena reputación, buena valoración y ese es uno de los triunfos que se adjudica esta concepción del mundo. Lograr la aceptación en el sentido popular, en el sentido común les facilita muchas de sus intervenciones tras el slogan de "todos podemos ser emprendedores". El objetivo de tal postulado, no solo apela a la masificación de este discurso emprendedor concibiendo a las personas desgajadas de sus contextos relacionales y estructurales, sino principalmente brega por que las cualidades emprendedoras preconizadas impregnen lo social (Leache y Sordoni, 2016).

A continuación, nos centraremos en el surgimiento y accionar de la fundación Endeavor para retratar los lazos, alianzas y espacios que comparten dichos tecno-emprendedores con emprendedores de otros sectores, con el afán de promover y replicar una subjetividad emprendedora.

\section{Endeavor, la fundación del emprendedor}

"La buena noticia es que cualquiera puede ser agente de cambio boy en día. No bay criterios de admisión. No hay voto secreto. El emprendimiento es para todos" (Linda Rottenberg, CEO y fundadora de Endeavor, 2019)

En su libro publicado en 2016, Linda Rottenberg, recuerda los comienzos de Endeavor desde Buenos Aires. Relata una conversación con un taxista porteño en el año 1997, cuando este mismo le comentaba que se había graduado en ingeniería pero que dadas las circunstancias coyunturales se encontraba teniendo ese trabajo. Linda, le pregunta si no había pensado en la posibilidad de convertirse en un emprendedor en lugar de conducir un taxi. Sorpresivamente, el taxista pensando que había oído mal, repregunta: ¿un empresario? Y es en ese momento, donde Linda advierte que no existía en el país una palabra que represente lo que ella estaba queriendo decirle; ser emprendedor estaba asociado con el término empresario, no con la acepción que en inglés prefigura: entrepreneur. De esta manera, lo que en principio avizoraba como un viaje ocioso se transformó, según sus palabras, en la creación de la fundación Endeavor: una organización que nuclee a emprendedores y que, en un futuro, fomentara la cultura emprendedora a nivel global.

En 1998, se reúne con Eduardo Elsztain, un empresario argentino del sector inmobiliario quien financia los comienzos de la fundación Endeavor. Así, de la mano de María Eugenia Estenssoro, Peter Kellner y Eduardo Elsztain, ese mismo año, nace en Buenos Aires, Endeavor. Actualmente, cuentan con 500 miembros, 54 oficinas en América del Norte, América Latina, Europa, África, Medio Oriente y Asia. En Argentina, inauguraron hasta el momento 6 oficinas que conforman, lo que denominan, "el ecosistema emprendedor nacional". Hablar de ecosistema, remite a una comunidad y un medio que comparten, dos cuestiones que cumplen les emprendedores. Manejan una red internacional de emprendedores que se mantiene latente a partir de eventos y reuniones pautadas anualmente y comparten un medio material concreto a partir de la instalación de oficinas en todo el mundo. 
La tarea que realizan desde la fundación está relacionada con dos focos, la selección y la promoción de servicios a emprendedores. Así lo explicaba María Julia Bearzi, directora ejecutiva de Endeavor:

\begin{abstract}
-Concretamente, ¿cómo apoyan a estos emprendedores?
- En el proceso de selección elegimos emprendedores de alto impacto que pasan por un proceso exhaustivo donde no sólo se los evalúa, sino que tratamos de agregarles valor. Se analiza su propuesta, las características de la persona y si es realmente un emprendedor de alto impacto. Una vez que es seleccionado se lo asiste con una batería de servicios pensados para impactar y trabajamos muy de cerca con ellos para conocer y entender sus desafíos y apoyarlos en eso, que generalmente tiene que ver con la expansión internacional. (María Julia Bearzi, 2019)
\end{abstract}

Ser "un emprendedor de alto impacto" o "un emprendedor diamante", en el ecosistema Endeavor, es un punto de llegada para quienes recién dan sus primeros pasos en las arenas del emprendedorismo. "Se refiere a individuos con las mejores ideas, el mayor potencial de crear negocios que importen y la mayor habilidad de inspirar a los demás", escribe Rottenberg (2016) en su bestseller. En Argentina, Endeavor reúne a reconocidos empresarios argentinos que realizan esa selección exhaustiva de los próximos potenciales emprendedores y a su vez, actúan como espejos de éxito siendo los consagrados emprendedores de impacto nacional ${ }^{16}$. Así, en el directorio actual de Endeavor Argentina, encontramos a los fundadores de dos de los unicornios latinoamericanos: Globant y Mercado Libre.

Estas dos empresas son puestas como ejemplos de trayectorias emprendedoras en cada evento que realiza la fundación y son un eje central de la propaganda emprendedora ${ }^{17}$. A su vez, Endeavor realiza periódicamente conferencias y eventos en donde la palabra autorizada de les emprendedores de alto impacto se abre lugar a la escucha de miles de potenciales miembros del ecosistema: Experiencia Endeavor, Gala Endeavor, Premios a los emprendedores del año, entre otros. Son una pieza fundamental del funcionamiento de la fundación ya que consolida una red de esparcimiento de los principios de esa cultura emprendedora en todo el país, respondiendo a la impronta federalista planteada desde la narrativa oficial, a partir de la cual, las locaciones de dichos eventos van rotando. En este sentido, las conferencias y los programas Endeavor, han retomado gran vuelo como nichos de capacitación y núcleo de futuras convocatorias de emprendedores. Experiencia Endeavor, por ejemplo, se realiza de manera anual, con una dinámica muy similar a las charlas TED. Consiste en una serie de entrevistas, conferencias de los principales emprendedores de alto impacto regionales, quienes comparten sus experiencias e interactúan con la audiencia presente, más una agenda de workshops de formación. Estas instancias de pedagogización colectiva, no solo buscan incorporar más miembros al ecosistema emprendedor sino también instar prácticas emprendedoras comunes como efecto contagio.

\footnotetext{
${ }^{16}$ Ellos son: Marcos Galperín (ex CEO de Mercado Libre), Guibert Englebienne (Co-fundador y CTO de Globant), Gustavo Grobocopatel (Presidente del grupo Los Grobo), Roberto Souviron (Fundador y CEO de Despegar.com), Martin Migoya (Co fundador y CEO de Globant), entre otros...

$17 \mathrm{La}$ red de contactos entre estos tecno-emprendedores y la fundación Endeavor se potencia cuando Linda Rottenberg (CEO y co-fundadora de Endeavor) asume como parte del directorio ejecutivo de la empresa Globant en el año 2017.
} 
En la edición 2017 de Experiencia Endeavor en la ciudad de Tandil, Martin Migoya fue uno de los entrevistados y al finalizar la entrevista con el moderador de Endeavor, una persona del público, le pregunto lo siguiente:

- Estas dando esta hermosa charla en una Universidad pública, vos estudiaste en una universidad pública. La pregunta concreta es: ¿Qué debería cambiar la universidad pública para aportar a la formación de esta actitud emprendedora según tu experiencia?

- (...) Voy a mencionar una sola cosa. La universidad nacional argentina pública me enseñó a mí a ser un fenomenal empleado de IBM. No tengo nada con IBM, es una gran compañía, pero yo creo que la universidad pública tiene que generar más empresarios emprendedores desde su fundación. Y enseñar que hay una conexión total entre el garaje en donde empezás y la multinacional para la que podés trabajar. Los argentinos, de repente, nos olvidamos durante 50 años que había una conexión entre las dos. Los jóvenes tienen que aprender que hay una conexión. Que Apple nació en un garaje, eso todo el mundo lo sabe, pero Microsoft también, HP también. Todas las empresas nacen en un garaje y no empiezan siendo mega corporaciones. Entonces, ¿por qué los argentinos no nos dedicamos a crear más de esas corporaciones? Hay que hacerlo, alguien lo tiene que hacer. ¿Quién es ese alguien? (señala al público) Acá, esta sala. Si hay un valor que yo enseñaría más en las universidades nacionales es esa actitud emprendedora y echaría luz al proceso de creación. Como Endeavor me ayudó a mí a pensar en grande cuando nos seleccionó en 2005, ese proceso tiene que darse no solo en un panel de Endeavor, sino que se tiene que meter en las universidades" (Martín Migoya, 2017) [subrayado propio]

Al entender de Migoya, la acción de emprender está vinculada directamente con crear corporaciones y recurre efectivamente al mito del garaje como forma de incrementar esa persuasión. Su crítica al sistema educativo acerca de la carencia de contenidos que fomenten la actitud emprendedora, expone hasta qué punto la expansión de esta filosofía empresarial es pensada por sus divulgadores. En otras palabras, Migoya sugiere el modelo de Endeavor como un ejemplo a ser retomado por las universidades públicas. Pensar a las instituciones educativas desde esa perspectiva, las ubica como prototipos de esos garajes de innovación de los cuales les futuros emprendedores surjan y asegura una masificación de los principios emprendedores en todos los sectores. En palabras de Daniel Fridman (2019): “el emprendedorismo ha dejado de ser una actividad particular para convertirse en una condición del yo que puede ser compartida por actores sociales tan dispares como el fundador de una gran empresa, un desempleado que vende comida en la calle, o una conductora de Uber" (p. 208). En este sentido, el alcance de su intervención discursiva se puede observar en lo cultural, lo educativo, lo laboral y como desarrollaremos a continuación, en la política partidaria.

\section{BA al mundo, el foro de Silicon Valley}

El 1 de diciembre de 2017, el Teatro San Martín fue la sede elegida por Endeavor y el Gobierno de la Ciudad de Buenos Aires para llevar adelante "El foro de Silicon Valley". "Cuando pensamos el lugar ideal para hacer el encuentro, sin duda era este porque, así como los artistas dejan su huella en la cultura, y al igual que los artistas, los emprendedores también dejan una huella en la cultura de nuestro país" comentaba la directora ejecutiva de Endeavor. Este evento, tenía como objetivo reunir a referentes mundiales del emprendedorismo, principalmente "líderes 
tech y de finanzas de Silicon Valley"18 y realizar un cruce con "la comunidad emprendedora local". Las inscripciones colapsaron, dejando a muchas personas por fuera del evento y ofreciéndoles la posibilidad de verlo desde sus casas a través de la transmisión en vivo.

Imagen $\mathbf{n}^{\mathbf{0}}$ 2: Flyer del evento (2017)

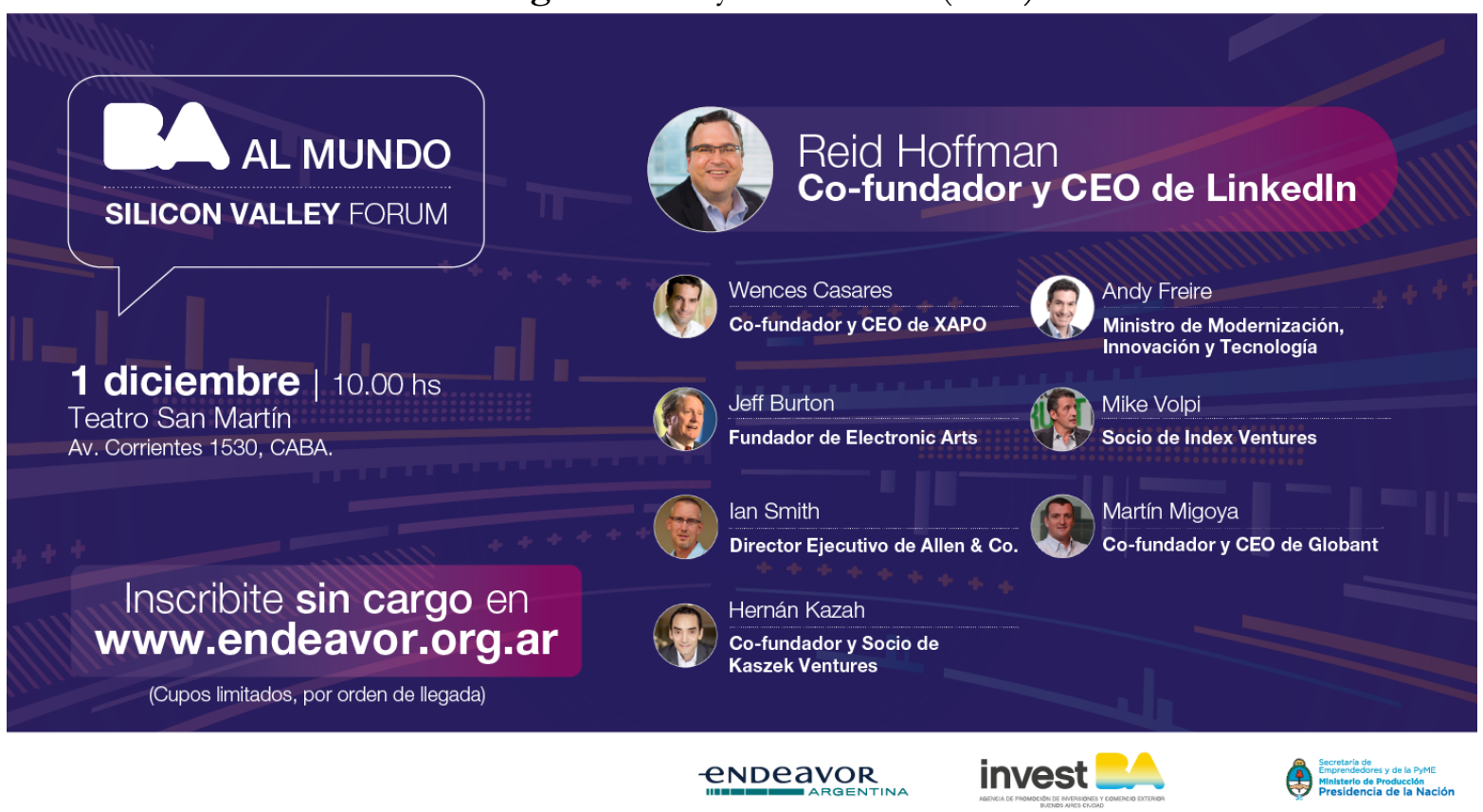

Fuente: Twitter oficial de Endeavor

Dos materiales audiovisuales dieron inicio a la jornada: uno de carácter institucional del Gobierno de la Ciudad, el cual reunía a los emprendedores de alto impacto de Buenos Aires promoviendo la Ciudad como la mejor locación que podrían haber elegido para emprender y finalizando con el slogan: "Es ahora". En segundo lugar, un video de Endeavor con motivo de los 20 años de la fundación que recorría su nacimiento- a partir de una idea- hasta la actualidad. Dos materiales audiovisuales que iban en una misma línea: promover la cultura emprendedora en la ciudad. El apoyo institucional que tuvo este evento desde el Gobierno de la Ciudad presidido por Horacio Rodríguez Larreta y del Gobierno Nacional, representado por el entonces Ministro de Producción, Francisco Adolfo Cabrera fue materialmente de gran relevancia y contó, a su vez, con los discursos de ambos funcionarios.

La verdad que es emocionante lo que hace Endeavor. Es un orgullo trabajar en equipo con ustedes. Estamos convencidos que el futuro de nuestro país y especialmente el de nuestra ciudad se basa en el crecimiento y desarrollo de las industrias basadas en el talento, en la economía del conocimiento (...) De los seis unicornios latinoamericanos, 4 surgieron en este país, y dos de esta ciudad. Y desde el gobierno, estamos dándole todo el impulso posible: desde el polo tecnológico, el distrito audiovisual, tenemos la academia "Buenos Aires emprende" en la que damos cursos de emprendedorismo y apoyo en todos los barrios de la

\footnotetext{
${ }^{18}$ Se encontraban presentes: Jeff Burton de la empresa de videojuegos Electronic Arts, Mike Volpi (Index Ventures), Santiago Subotovsky (Emergence Capital), Hernán Kazah (Kaszek Ventures) e Ian Smith (Allen \& Co) y Reid Hoffman (LinkedIn).
} 
ciudad. Y esto más allá del estado, lo vamos a conseguir trabajando juntos (Horacio Rodríguez Larreta, 2017).

Como dijo Horacio, Buenos Aires se ha transformado en una ciudad más vibrante y energética de Latinoamérica y esto tiene mucho que ver con el espíritu emprendedor, con lo que estamos viviendo acá. La buena noticia es que ahora hay un solo equipo, el equipo de la Nación, la ciudad que se replica en toda la argentina. Clubes de emprendedores, ciudades de emprendedores, polos de la innovación y algo que se ve que está en el ADN de los argentinos. Y nosotros los consideramos héroes a los fundadores de estos unicornios y querríamos tener muchos más, querríamos clonarlos para tener muchos más de ellos. Hace muy poco lanzamos una Ley de emprendedores, que esperamos se implemente pronto, que permite, por ejemplo, hacer una sociedad en 24 horas (Francisco Adolfo Cabrera, 2017).

Desde el cambio en la gestión gubernamental en el año 2015 en Argentina, en la cual asume el gobierno de corte neoliberal de Mauricio Macri, el discurso emprendedorista ha tomado un protagonismo inusitado en las intervenciones de los funcionarios públicos afines a la alianza "Cambiemos". Si pensábamos que los discursos de los emprendedores de alto impacto seguían una linealidad discursiva en sus experiencias, ahora podemos sumar a estos funcionarios públicos del partido PRO dentro de ese andarivel. La retórica utilizada tanto por Horacio Rodriguez Larreta como por Francisco Cabrera, da cuenta de cómo la visión empresa es exacerbada hasta el punto de considerar a los tecno-emprendedores como "héroes". Como señala Javier Moreira Slepoy (2018), el discurso neoliberal en tanto proceso de político de subjetivación produce una novedosa articulación con el emprendedorismo estableciendo al emprendedor como su modelo subjetivo ideal. La subjetividad emprendedora que el sector empresario buscaba expandir con Endeavor, encuentra dentro de un gobierno neoliberal un terreno fértil y las herramientas institucionales para traducir todo ese discurso a las prácticas públicas. Son esas reivindicaciones políticas de apertura al mundo, de contacto simbiótico con el mundo empresario las que potencian al emprendedorismo. En ese escenario, los tecno-emprendedores siendo exponentes de un sector que potencia la innovación y se encuentra en creciente expansión en el capitalismo contemporáneo, son catalogados como una promesa de futuro basada en la mediación tecnológica y en la creación de empleo. La mentalidad emprendedora es vista, por tanto, como una cualidad moral asociada al éxito económico y que puede transferirse al ámbito de la política (Vommaro, 2014) convirtiéndose en una propuesta de política pública tratada seriamente como herramienta para paliar la pobreza, el subdesarrollo, la desigualdad y el desempleo (Fridman, 2019). Tal como expresa Nicolás Cuello (2020), los movimientos de reorganización de la política neoliberal latinoamericanos se apoyan en una subjetividad mediada por la matriz empresarial de la verticalidad meritocrática y el consenso pacificador intentando extender de forma proporcional programas políticos para erradicar de sus imaginarios la cuestión tóxica de "lo político". Así, cualquier esbozo de resistencia, organización colectiva, disidencia a este discurso son presentadas como amenazas "ideológicas" a los planes de un futuro prometedor, como el alcanzado por estos tecno-emprendedores. En definitiva, el tecno-emprendedorismo como concepción de mundo del capitalismo contemporáneo, expresa una articulación de intereses políticos, económicos, culturales, intelectuales y morales que cristalizan el devenir hegemónico de una generación empresaria revitalizada bajo el paraguas de la innovación tecnológica. 


\section{Reflexiones finales}

A través del presente trabajo, intentamos reconstruir ciertas particularidades que hacen al tecnoemprendedorismo consolidarse como una concepción del mundo en el capitalismo contemporáneo. Indudablemente el mito del garaje, que aúna el origen de muchos de los imperios tecnológicos de Silicon Valley, tiene un lugar fundamental en la construcción del discurso tecno-emprendedor. En términos simbólicos, podemos decir que la exaltación del garaje resalta dos ficciones emprendedoras: en primer lugar, la idea de que cualquier persona puede emprender y, en segundo lugar, que las experiencias de tales gurúes tecnológicos pueden ser replicables. En Argentina, las empresas denominadas unicornio, adaptan el mito del garaje a sus unidades de negocio y situación geopolítica. El caso de la empresa Globant, es un ejemplo de esto último. Sus cuatro socios fundadores en reiteradas ocasiones refieren al origen de la empresa como el resultado de una charla en un bar, un presupuesto mínimo pero una gran potencia emprendedora. Aquí, la meritocracia se convierte en el plan de acción perfecto para ser un tecnoemprendedor y refuerza otro mito: el de la igualdad de oportunidades. Quienes asumen riesgos, sortean obstáculos, no se rinden, son quienes pueden contar el próximo mito del garaje.

La confluencia de los tecno-emprendedores en la Fundación Endeavor y el rol que cumplen para esta institución, da cuenta del alcance de sus prácticas y el anhelo por expandir el discurso emprendedor. Siendo catalogados como "emprendedores de alto impacto" son situados como ejemplos empíricos propagandísticos para los potenciales emprendedores que dicha fundación busca apadrinar. Ahora bien, ¿Por qué emprendedores y no empresarios? El sujeto emprendedor representa una renovación de los tradicionales principios empresarios y el tecno-emprendedor, en particular, refuerza esta idea a partir de su ligazón con el desarrollo tecnológico. La relación entre la acción de emprender y la tecnología se vuelve crucial para profundizar esa brecha simbólica con viejas formas de gestión empresarial. Así, quienes dicen estar al frente de las empresas del futuro se presentan como una superación de las gerencias tradicionales y en constante renovación al calor de últimos desarrollos en materia tecnológica. En este sentido, el tecnoemprendedorismo como concepción del mundo de esta nueva fracción de empresariosemprendedores fagocita una idea de progreso y de un buen vivir relacionado con las nuevas tecnologías y es en esta promesa de futuro, que las tensiones con las tradicionales gestiones empresarias se cristalizan.

Asimismo, esta concepción de mundo contemporáneo consigue el aval y la reproducción de sus prácticas discursivas en la esfera pública. El foro de Silicon Valley realizado en Buenos Aires en el año 2017, visibiliza marcadamente la narrativa emprendedora en los discursos de dos funcionarios públicos de un gobierno de corte neo liberal como ha sido el del ex presidente Mauricio Macri (2015-2020). La meritocracia, la idea de progreso y la apertura al mundo se suman a referencias sobre inquietudes y compromisos con la sociedad, la ecología, los valores humanitarios y democráticos (Bueno Castellanos, 2020). En este sentido, el famoso slogan de campaña del gobierno de Mauricio Macri "si se puede" congenia perfectamente con el propósito del "mito del garaje": potenciar ficciones emprendedoras que oculten relaciones sociales asimétricas e individualicen las prácticas. Allí, el discurso neoliberal de la alianza Cambiemos funciona casi como experimentador histórico (Gramsci, 2000) de tal concepción de mundo.

Por lo expuesto hasta aquí, el tecno-emprendedorismo argentino no solo se prefigura como un caso de éxito entre sus pares emprendedores, sino que trasciende a otros ámbitos y sectores que retoman sus trayectorias como parte de una propaganda de subjetivación emprendedora. 
Ahora bien, los interrogantes que se abren para futuras aproximaciones son: ¿Quiénes pueden y no pueden emprender? ¿Qué trayectorias habilitan esta idea de movilidad social emprendedora en ámbitos ligados al desarrollo tecnológico? ¿A quiénes interpela este discurso? ¿Cómo se relacionan estas narrativas con la brecha digital de género? ¿Cómo se adaptan estos discursos a momentos de crisis donde las desigualdades quedan al descubierto, como en el caso del contexto de pandemia de COVID-19?

Al decir de Antonio Gramsci (2000b), las diversas concepciones del mundo se encuentran en disputa o contradicción con otras, por lo tanto, será cuestión de continuar profundizando el análisis crítico para lograr tensionar esas neoliberales promesas de felicidad.

\section{Referencias}

Bueno Castellanos, C. (2020). Ser emprendedor en el México del siglo XXI. Universidad autónoma del Estado de México.

Bröckling, U. (2015). El self emprendedor: Sociología de una forma de subjetivación. Ediciones Universidad Alberto Hurtado.

Castells, M. (2017). La era de la información. Alianza.

Cuello, N. (2019). Presentación: El futuro es desilusión. En Ahmed, S. La promesa de la felicidad. Una critica cultural al imperativo de la alegría, pp. 11-20. Caja Negra.

Dubet, F. (2014). Repensar la Justicia Social. Contra el mito de la igualdad de oportunidades. Siglo Veintiuno Editores.

Endeavor Argentina [Endeavor Argentina]. (01 de diciembre de 2017). BA Al Mundo: Silicon Valley Forum [Archivo de Video]. https:/ /www.youtube.com/watch? $\mathrm{v}=\mathrm{vfFu} 9 \mathrm{mf} 8 \_\mathrm{t} 4 \mathrm{kt}=296 \mathrm{~s}$

Endeavor Argentina (21 de Junio de 2017). Experiencia Endeavor Tandil 2017, Martín Migoya Co-fundador y CEO de Globant [Archivo de Video]. https://www.youtube.com/watch?v $=\mathrm{uAKfQm} 5 \mathrm{sct} 0$

Endeavor Argentina (30 de Enero de 2017). Martín Migoya - Fundador y CEO de Globant | Experiencia Endeavor Rosario 2016. [Archivo de Video]. https://www.youtube.com/watch?v=qp2x2Q_fPU0

Englebienne, G. [Emprendiendo TV]. (29 de Julio de 2019). Globant: Lecciones de un unicornio argentino que conquista el mundo [Archivo de video]. https://www.youtube.com/watch?v=pRGecDV1oCU

Englebienne, G. (25 de octubre de 2019) ¿Puede la tecnología ayudarnos a construir organizaciones más humanas? Blartmeup. https://www.starmeup.com/blog/es/cultura-organizacional/puede-la-tecnologia-ayudarnosa-construir-organizaciones-mas-humanas/

Fridman, D. (2019). El sueño de vivir sin trabajar. Una sociología del emprendedorismo, la autoayuda financiera y el nuevo individuo del siglo XXI. Siglo Veintiuno Editores.

Girón, A. (20 de enero de 2019). Endeavor cumple 20 años en el país: el rol de los emprendedores en la crisis y qué se viene en 2019. IprouP. https://www.iproup.com/startups/2176-endeavor-rol-de-los-emprendedores-en-la-crisis-ylo-que-viene-en-2019 
Gramsci, A. (2000a). Apuntes para una introducción y una iniciación en el estudio de la filosofía. En Cuadernos de la cárcel. [Edición crítica de Valentino Gerratana]. Tomo 4. México: ERA. pp. $245-261$

Gramsci, A. (2000b). Algunos aspectos teóricos y prácticos del «economismo». En Cuadernos de la cárcel. [Edición crítica de Valentino Gerratana]. Tomo 5. México: ERA. pp. 40-47.

Misiones Online (30 de septiembre de 2020). La Universidad del Conocimiento de Silicon Misiones inscribe para su oferta en desarrollo de software y programadores. https://misionesonline.net/2020/09/30/universidad-del-conocimiento-cursos/

Moreira Slepoy, J. (2018). Discursos y lógicas en la construcción de "otra economía" en Argentina. Prácticas y discursos, 7 (10), 109-131.

Moruno, J. (2015). La fábrica del emprendedor. Ediciones Akal.

Leache, P. A., y Martínez, L. (2016). La subjetividad puesta a trabajar: Identificación y tensiones frente al ideal del emprendimiento. Con-ciencia social: anuario de didáctica de la geografía, la historia y las ciencias sociales, (20), 43-56.

Lopez Puga, J. y García, J. (2011). Optimismo, pesimismo y realismo disposicional en emprendedores potenciales de base tecnológica. Revista Psicothema, 23 (4), 611-616.

Palermo, H.; Radetich, N. y Reygadas, L. (2020). Trabajo mediado por tecnologías digitales: sentidos del trabajo, nuevas formas de control y trabajadores ciborg. Revista Latinoamericana de Antropología del trabajo. 4 (7), 1-35.

Porcella, V. (27 de noviembre de 2018). Galperín, Migoya, Englebienne: el nuevo establishment. Forbes Argentina. https://www.forbesargentina.com/negocios/empezo-sacando-fotoseventos-sociales-hoy-elegido-grandes-marcas-n7096

Ribeiro, L. G. (2017). El precio de la palabra: la hegemonía del capitalismo electrónicoinformático y el googleísmo. Desacatos, (56), 16-33.

Rottenberg, L. (2016). Loco por emprender. Desafia las normas convencionales. Penguin Random House, Grupo Editorial México.

Sadin, E. (2018). La silicolonización del mundo. La irresistible expansión del liberalismo digital. Caja Negra. Santos Ortega, A. (2014). La política en manos de los empresarios: el imparable ascenso de la ideología del emprendedor. Papeles de relaciones eco sociales y cambio global. (127), 29-43.

Schumpeter, J. (1997). Teoría del desenvolvimiento económico. Fondo de Cultura Económica.

Silicon Misiones (08 de septiembre de 2020) Webinar "El Camino del emprendedor" Telefónica Open $\quad$ Future. [Archivo de video]. https://www.youtube.com/watch?v=HiWrPJxjvs4\&ab_channel=MolRedaccion

Srnicek, N. (2018). Capitalismo de plataformas. Caja Negra.

Vanolli, H y Galliano, A. (2017). Los dueños del futuro. Planeta.

Ventrici, P.; Krepki, D. y Palermo, H. (2020). "Sector software y la situación respecto de la pandemia de COVID-19", Informe $\mathrm{N}^{\circ}$ 2. Buenos Aires: CEIL-CONICET.

Ventrici, P., \& Palermo, H. M. (2021). La siliconvalización del trabajo. Una experiencia argentina. Íconos. Revista de Ciencias Sociales, (69), 201-218.

Vercellone, C. (2011). Capitalismo cognitivo. Renta, saber y valor en la época posfordista. Prometeo.

Vommaro, G.; Morresi, S. (2014). Unidos y diversificados: la construcción del partido PRO en la CABA. Revista S.A.A.P, 8, (2), 375-417.

Zuboff, S. (2019). The age of surveillance capitalism. Profile Books Ltd. 